\title{
Rolling with the punches
}

\section{Sharyn Rundle-Thiele, Julia Carins and Christiane Stock}

Much of our professional practice is underpinned by the cycle of planning. Most research projects require a plan to be set during the funding application process, which establish expectations for colleagues working in the project to ensure that reports on milestones and deliverables at particular stages are clearly communicated to all research stakeholders. We all know that planning has many benefits. The process of planning helps us to set objectives, which for many of us increases the likelihood that things will be completed, making an eventual outcome (a published paper, a presentation, thesis or report) more likely. Another key benefit delivered by the process of planning is that it compels us to set a course of action to achieve the objectives that we set and ideally we should meet form time to time during the process to make sure we are on track to deliver.

In academia we are encouraged to network which allows us to share our knowledge and learn the languages needed to clearly communicate our work to others. Universities across the globe encourage partnerships with other universities, industry, the non-profit sector and the governments who fund our work. To deliver the large scale and long-term projects needed to deliver cutting edge science researchers work within the networks that they have established. To deliver the largest projects we must form and maintain working relationships with other academics and practitioners. In this way we can deliver results in a way that we provide cutting edge science while meeting the needs of project stakeholders. For example, the research work that we do can help our research partners to solve a problem, improve their processes or through discovery can uncover new technologies and ways of practising.

As a Masters or PhD student, an early or mid-career researcher, or even an established or senior researcher, the start of a research project generally involves the creation of a supervisory or advisory team. The rationale for creating an advisory team for a research project is to provide support to progress and complete the research agenda delivering a contribution that advances knowledge in your field of science. When the particular research project forms the basis of your $\mathrm{PhD}$ candidature, or when you are an early or mid-career researcher working within a team for the first time, you will be confronted with additional challenges. Your performance 
within the team will be carefully considered by your senior colleagues and your work will be evaluated and judged. Your performance will be directly compared to the performance of your peers, which naturally creates competition. If you can perform as a valued member of a team, it is likely you will be retained within the team beyond that project, or recommended to colleagues in your advisory team's networks. If your performance exceeds your peer(s) your ongoing employment prospects are further enhanced. At a team level a reputation for delivering on time, every time, and within budget, will ensure that you are competitively placed to win future projects which also helps to build research capacity by creating jobs keeping junior members of the team employed.

Regardless of your role in the research project - as a project leader, senior team member, junior team member, assistant or research student - working within a network to deliver your project on time, and for some within budget, is a challenge given your project is reliant on others. You need to learn to work effectively and create a network that helps you all to deliver more synergistically, and in a way that strengthens the efforts of each member - without being seduced into trying to win at all costs.

So what happens when plans fail? We all know that the very best plans can and do fail, and this is why we wanted to share our stories with you. If you are a high achieving individual (if you are reading this it is likely that you are) you are used to being in control and are probably very capable of delivering on time all of the time (or at least most of the time). By sharing our stories with you we want to help you to know that it is really important to learn to roll with punches. If you can overcome the obstacles blocking your path with a smile and positive attitude you will be viewed more positively than colleagues whose behaviours are negative and counterproductive. There is no point yelling at people, having a tantrum and engaging in any form of negative behaviour. Simply approach your project as though things will go wrong. Being prepared for this possibility means you will be better equipped if things do go wrong. This means that you need to plan extra time or larger research designs for the things you can't see, don't yet know and for the others you are working with (bearing in mind the composition of the team may well change by the end of a multi-year project). The contingency of extra time leaves you with less pressure when the inevitable goes wrong. 


\section{Stepping out of a controlled environment into the field - dealing with unpredictability}

Field research provides a number of opportunities to gain valuable insights into phenomena of interest, or to empirically determine whether any strategies devised through research can be successfully transitioned into practice. For these reasons we consider that research conducted "at the coal face" as an indispensable part of the research process - the litmus test of whether a theorised occurrence plays out as intended, or whether a recommendation results in the intended benefit. Whether you are a novice or an experienced researcher, conducting field research, or collecting data beyond the laboratory or controlled environment can evoke feelings of both excitement and terror.

Field research can be incredibly motivating and inspiring-providing the opportunity to observe complex behaviours playing out in dynamic environments in order to advance our understanding. At the same time field research can also scare the hell out of us. We often head out into the field with fears both imagined and real. The real fears come from the experience of what has gone wrong in earlier field trips, while the irrational fears can be even more daunting. Consider some of the many things that can and do go wrong - a flat battery in a research device, forgetting to hit record on an audio recorder, server breakdowns, power outages - right through to an aberration in the space time continuum which produces a weird alternate universe, and in turn produces data that is meaningless or completely contradicts everything that is already known in the field (we did say irrational!).

Julia Carins' research adopts a social marketing lens to understand eating behaviour. The aim of her $\mathrm{PhD}$ research was to devise strategies that result in healthier eating practices in order to increase health, performance and wellbeing, within a workplace setting. Her work was sponsored directly by her employer, and was client partnered research. Over the course of her $\mathrm{PhD}$, Julia applied a mixed method approach to capture what individuals choose to eat, and to understand what influences people to make those choices-whether they be individually motivated, or driven by the surrounding environment.

One of the methods that Julia employed in her mixed method study was observations. Observations provide the opportunity to objectively capture what individuals do rather than relying on self-reports of their actions, which are subject to both memory and social desirability biases. Julia's work has used both manual observations (structured observations with accompanying field notes) as well as photographic techniques. Using a structured observational technique requires preparation to ensure that the aspects of the behaviour of interest can be 
observed and quantified in a reliable and meaningful manner. This involves starting with sessions in the chosen context, to understand what elements are important and relevant, as well as what feasibly can be captured in the data collection instrument (structured observation sheet). These early sessions provided Julia with practice, allowing her to get a sense of what was occurring, to determine where the best vantage points were, how fast the "action" was, what discrete actions should be recorded... and so on. In many ways, Julia used these early sessions to troubleshoot, and feel confident that once she started the structured observations sessions nothing could possibly go wrong...

Until it did.

Julia's $\mathrm{PhD}$ project involved observing diners making food selection choices in a workplace buffet-style cafeteria. She planned to use photographic techniques to capture individual food choices, and to then pair these data with manual observation techniques to examine patterns within the dining room. The photographic technique essentially meant approaching diners at the point where they finish making choices from the buffet counters, and asking to photograph their plate of food. This would provide a data set for later examination, allowing Julia to quantify the types of foods being chosen on an individual basis, and equipped with the caterer's menu and some leading nutritional analysis software; she could then determine the healthfulness of the choices made at lunch and dinner. Of course as this was a busy cafeteria, she was not able to photograph the plates of every diner-so this set of photographs would provide information about the food choices of a subset of diners at each meal. The manual observation involved a team of observers stationed at various points in the dining room (near each of the buffet counters) to record each time a diner made a selection from the dishes available. This provided a data set of all of the selections being made in the dining room$100 \%$ coverage - but at a dish level rather than an individual level. This allowed Julia to correlate the two data sets - to ensure patterns observed in the smaller photographic subset were representative of the patterns in the cafeteria as a whole, and also to examine 'popularity' of particular dish types.

Preparation for data collection progressed according to plan; Julia had visited the cafeteria a number of times to see the 'lay of the land'. She had noted the fast paced, but predictable traffic flow-where people enter, how they progress past the counters, where they exit the food area to find a seat to consume the meal. She had noted approximately how many diners attend for lunch, and dinner, and started to map in her head where observers would need to stand to record 
data. It was quite a large space — only ever about half full— there were spare food counters that the caterers said they only used when they had extra groups in for training. An observation template was prepared to structure observations of food selections, and a team of observers were organised to observe four meals (two lunches and two dinners on different days) to test the data collection methods devised for the projects. This test aimed to make sure that it was possible to record everything needed to capture data for the project. Everything ran smoothly. Julia followed this data set through to analysis to ensure that the data collection and analytical approach was sound, and that it actually produced the kind of insights she expected. It did! She believed the data collection approach was ready to be used during field experiments- to measure the effect of the healthy eating strategies she and the research team had planned to deploy in this setting.

Julia planned her data collection days, taking care to avoid training weeks, and started premeasures ahead of strategy implementation. The first meal observed by Julia and the team ran like clockwork. Just like the other meals they had observed during preparation, the first ten minutes were the busiest - as those who had been waiting in a queue filed through. The rest of the meal was a steady stream of diners. It was the second meal where things started to unravel. The busy rush persisted during this particular evening meal, diners were almost running into each other...serving themselves seemed like a table of discount kitchen utensils during a Boxing Day sale - tongs and spoons going everywhere! Fortunately Julia's data collectors were well caffeinated, and with some very intense focus were still able to capture the selections. Until...unannounced...the caterers opened a second serving point. It took Julia a few minutes to notice as she was busy photographing plates (what the...?!). Half of the queue migrated to the new servery, but there was no spare observers to cover the new servery! Julia and her team were no longer able to monitor the entire dining room, meaning that data set would no longer be complete. This also had implications for her photographic data set, as she could no longer compare the two to give the required confidence that the subset was representative of the larger dataset. Julia finished observation of the meal with a sense of dread that the entire session was a waste.

The most predictable thing about field work is that it is totally unpredictable. Things change very quickly, and even with a carefully prepared and pre-tested data collection strategy you can be caught off guard. Although Julia had liaised with the caterers beforehand and they understood what she was trying to achieve, they were focused on delivering a good service, and research requirements were possibly the last thing on their minds during the meal itself. 
Julia was fortunate - she had planned to collect data from a number of observation sessions, so she could afford to ditch one incomplete data set. Our institute was also able to bring another research assistant on board for future sessions in case it happened again (it didn't).

\section{Taking the good with the bad - navigating and negotiating with clients and partners}

Imagine this scenario. You have been working together for months. Over the months, you have agreed on a research plan, designed and executed your first study in this new partnership. During the project you have collected and analysed data to meet the research objectives set for the project. All of this work has been compiled into a report which is tabled to the research partner and your next course of action becomes apparent. By successfully delivering the first agreed project on time and within budget the people you work with in your partner organisation are highly supportive of your work and they would like to progress into a new phase of work. They are so happy with your work they have now introduced you to colleagues and your reach within the organisation has grown. This is evidence that your work practice is sound, and that you have delivered scientific and rigorous research while also being able to meet your project partners goals. The future is looking rosy. Work commences on the next project phase and everyone is really looking forward to seeing the outcome with some testing in the field locked in.

And then it all goes wrong.

The Director doesn't approve the field work plan, the research partner won't allow you to publish the findings due to reputational concerns, or the project is put on hold due to extenuating circumstances. These are all examples that we have been faced with and on far more occasions than you would like to think.

The largest projects we work with are funded by one or more organisations and in these large projects, work is delivered in collaboration with academic colleagues within your own university, across universities, and by practitioners or specialists within partner organisations. Working in funded projects with research partner organisations definitely has it benefits, which include (but are not limited to) access to respondents, data and the financial and human resourcing to deliver work at a level you just simply can't achieve on your own. Perhaps most importantly in our line of work, which is social marketing and public health, the opportunity to deliver funded projects allows us to be personally involved in the delivery of behavioural 
change. While testing messaging we can be simultaneously be changing attitudes towards violence; while conducting research we can be raising awareness for very important causes (e.g. organ donation); and importantly when we are testing programs and interventions in the field we can also be delivering behavioural change (increases in healthy eating or decreases in alcohol drinking). Working in the field, in partnership, delivers first-hand experience of the impact of the research work that you are undertaking, which is motivating; helping you to stay focussed on your research work. Large funded projects delivered in partnership with organisations and collaborating academics offer many benefits, but there can be downsidesgoals can differ, and some people simply don't deliver on their promise. Together, these can deliver a host of unforeseeable problems.

Quite often we are asked for advice to help navigate this highly competitive world we work in. Our advice is simple. Try to network and through your networks build a team of people that you can trust to reliably deliver on time, every time. Don't be seduced by a big name in the field; instead take your time and understand their work practice. You want to know you are about to work with someone who will give as much as they get from you in return ensuring that you both benefit from working together over time. We recommend you start with a small, tightly defined piece of work to see if working together is mutually beneficial and that you increase project size and scope as you gain confidence that you have found a mutually beneficial working relationship. That early test can save a lot of long-term pain by revealing the people that work well with and for you; and giving you the opportunity to say "thanks, but no thanks" to future projects with those people with whom it didn't work so well.

When it comes to working in large teams there are ways to avoid problems over the course of the project. For example, on project commencement we recommend, as a team, you develop a clear plan to guide the program of work assigning clear tasks to team members to meet project milestones. You should also think about publications that will eventually arise from the project. Once again, within large projects we recommend you develop a publication plan with the team on project commencement, assigning authorship and responsibilities for the publications that are expected to arise from the project. Make sure you are familiar with rules governing authorship and intellectual property rights and where you are in doubt seek advice. Too often we see senior academics claiming authorship on papers citing old rules of thumb which have been passed down over academic generations. When negotiating authorship and developing publication plans, be clear about the activities constituting authorship for each individual piece of work. To be an author on a paper a co-author needs to be able to demonstrate clear evidence 
of one or more of planning the research design; undertaking data analysis and interpretation; and/or drafting or critiquing the manuscript so as to make a substantial contribution to that piece. Too often, academics claim involvement when no evidence of delivery exists. Establishing expectations from the outset and carefully managing progress during the course of the project can help to keep teams working functionally, which is better for everyone in the long run.

Establishing plans is always recommended, because collaboration within larger teams or consortia has many benefits, including scientific gains (e.g. through the acquisition of larger datasets, acquisition and development of new knowledge) and the ability to develop synergies allowing more work to be delivered. Working in partnership is indeed required in the cases of grant applications to major funding bodies, but it is important to acknowledge the best plans can and will fail. Extenuating circumstances will arise outside of the project that can impact the project, and it is in the face of the biggest challenges that clear communication, and your own willingness to compromise, is needed. Projects can be derailed within a funding organisation for reasons beyond the control of the direct project team you are working with (e.g. change of government with a new government no longer backing the project). It is at these most challenging times that your response matters the most. While getting the original short term outcome may seem to be the most important, we know that an ability to be flexible and find 'work arounds' could offer a much greater gain in the longer term. Our advice is when the worst happens to you, do not pick up the phone, type an email or speak until at least 24-48 hours after notification. It is important you give yourself the time needed to rationally (and not emotionally) think of solutions to overcome the challenge that has emerged.

\section{Be prepared and be flexible - what doesn't kill you makes you stronger!}

Research is a wonderful life. There are few jobs that provide the flexibility and freedom to pursue a topic that you are passionate about. Any project that you are responsible for (especially your $\mathrm{PhD}$ project as your first independent research) requires you to apply project management skills to deliver the project on time and within budget. Those who are attracted to research as a career understand it is a very competitive landscape. From Day One you are competing with your $\mathrm{PhD}$ peers or with other more senior research staff. We are all different, and it is important that you stay true to yourself. To navigate the complex social setting that is research, you need to carefully consider what is important to you knowing that each and every decision that you 
take can and will have repercussions. We urge you to roll with the punches, knowing this is not easy at all. If you love research as much as we do you are here for the long term. You have one reputation and what you do and say will be judged, remembered and, unfortunately, in some cases it may be held against you.

So do all the things we do (be prepared), be flexible where you can and then expect the unexpected. Working outside a controlled environment is exactly that - uncontrolled. But it is real, and it is exactly where you want to apply (at least some) of your research skills- to demonstrate that your research delivers impact in a dynamic world.

We recommend that you build research partnerships, and think long term. The best research comes from a body of work undertaken over time and this can only occur if you can establish strong, long-lasting relationships where the people you chose to work with deliver work for you as much as you deliver work for them. Do your homework and seek people who deliver work for you - preferably on time, every time. There is certainly no formula to clearly guide you. Don't be fooled by gossip and other people's opinions. Do ask questions of the people around because forewarned is forearmed but be prepared to give someone a chance if you have that feeling that you may complement. We are all different and this means that a person you work well with may not work well with another person that you work with. We advise you to search for people with a mixture of academic and personal qualities that match (or complement) your own qualities. Search for those who work similarly to you, where you each provide strong skills in areas where the other may not be as strong, and even those who challenge or inspire you. And if you happen to be working with others not of your choosing - look for these things in those people. By finding such people (or those qualities within people) you will unfold your full potential.

\section{Lessons for rolling with the punches}

- Always be one step ahead - don't plan to fail, but recognise that it will happen, and plan to be able to respond or make changes if it does.

- Outline and communicate (or be aware of) the responsibilities each person has within a project - this can help keep the team on track and save unnecessary conflicts arising. 
- When calamity strikes, don't act immediately - give yourself time to take a step aside and consider the entire situation - to see the full picture and to think rationally. You will win in the longer term by being kind and seeing it through someone else's eyes.

- Stay positive and smile - people are in this game for a long time and once burnt, some bridges can't be rebuilt.

- Know that what happened was meant to be - today's obstacle may be tomorrows blessing, and even if it isn't, you will be better equipped to avoid that obstacle next time.

- Try before you buy - start building your networks by testing people out on small projects, keep the winners and politely ditch the others.

- Remember there is no ' $\mathrm{I}$ ' in team - large projects require many people and team players will be stronger academics in the long run.

- Find the people who work for you and with you, not only will you create a smoother ride, but synergies that benefit all.

- Recognise that support goes both ways and all ways, from the mentor to the mentee, from the assistant to the leader, and between peers within projects and across networks. Give as much as you get.

- Know the rules of the game - and play within the rules of the game. Also know that the rules change over time. Just because it once was doesn't mean it always should be. This applies to publishing, IP, research agreements and roles and responsibilities.

- Finally, take a moment once in a while to reflect on the path you have chosen. Following your passion for research can be very rewarding - even when things do go wrong! 